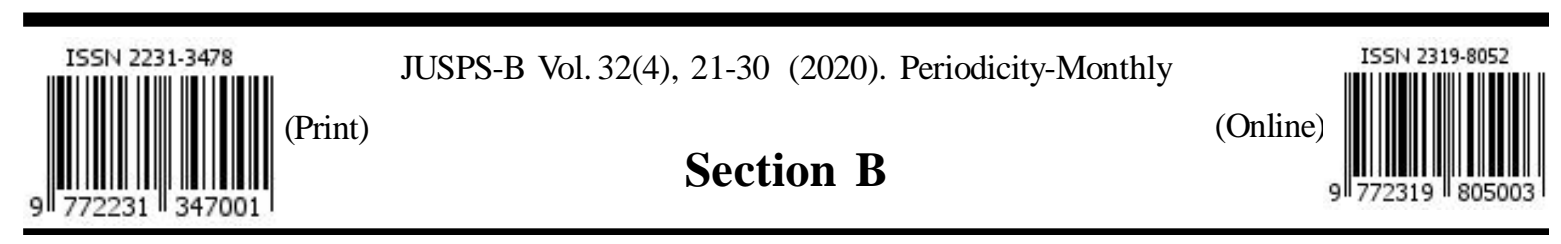

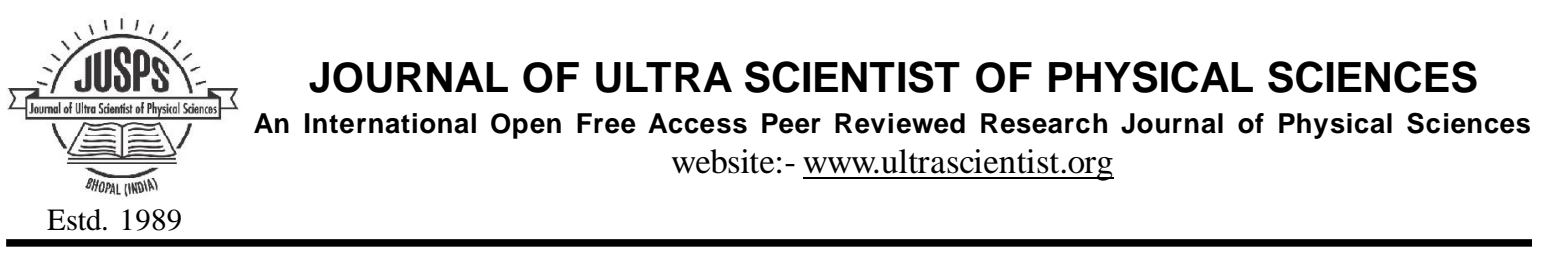

\title{
Performance Enhancement techniques in vapour Compression refrigeration system by various evaporator loads and thermoelectric sub cooling
}

\author{
SYED DANISH SYED ABDULHAMEED ${ }^{1}$ and D.C. VISHWAKARMA ${ }^{2}$ \\ All Saints' College of Technology, Bhopal \\ Email of Corresponding Author :- syeddanishmalik@gmail.com \\ http://dx.doi.org/10.22147/jusps-B/320401
}

Acceptance Date 17th October, 2020, Online Publication Date 19th October, 2020

\begin{abstract}
Part load performance analysis on simple VCR system using selected refrigerant mixture at different loading conditions is completed to identify the economic mode of loading in the evaporator. In this research work, evaporator has been loaded at different loading (thermal loading - cooling of liquid substance in the evaporator) conditions like 25, 50,75 and 100\% of its capacity based on its volume and water is considered as a substance to be cooled in the evaporator for analyzing the performance of the refrigeration system at different loading conditions. The cooling temperature $\mathrm{C}$ and the condensation process has range of water is considered from 26 to 2 been carried out by Atmospheric Air Circulation (AAC) mode. The various performance indexes of refrigeration systems namely work input to the compressor, condenser heat rejection rate, refrigerating effect and COP are obtained based on unit mass flow rate of the refrigerant in this analysis. Experimental results suggest that $75 \%$ loading condition is the significant one among other loading conditions in the evaporator.

Experimental analysis has been carried out with $3^{\circ} \mathrm{C}$ of subcooling in the VCR system with thermoelectric subcooling and various performance indexes are investigated with reference to water temperature in the evaporator at different loading conditions. Significant improvements in various performance indexes have been obtained for VCR system with thermoelectric subcooling. The experimental results clearly state that $75 \%$ loading condition gives the highest $\mathrm{COP}$ at lowest temperature of evaporator substance. Among various loading conditions, $\mathrm{COP}$ of $75 \%$ loading condition is about $6.7,3.9$ and $25.13 \%$ higher than that of 25,50 and $100 \%$ loading conditions respectively.
\end{abstract}

Key words: thermoelectric subcooling, VCR system, Refrigerating effect, Power consumption, COP.

This is an open access article under the CC BY-NC-SA license (https://creativecommons.org/licenses/by-nc-sa/4.0) 


\subsection{Introduction} Background

Perkins has developed the first refrigeration machine in 1834 with hand operated compressor and ether as a working fluid. Later, Gorrie developed an air refrigeration system in 1851 and Linde has introduced a refrigeration system with ammonia as a working fluid in 1856. During this initial stage prime movers used to run the compressor was the major issue. Due to the advancements in electric motors and compressors, progressive achievement was made in due course. James Harrison developed the first Vapour Compressor Refrigeration (VCR) system and constructed a mechanical ice making machine with ether as a working fluid. In 1870s, refrigerants like sulphur dioxide, methyl chloride and carbon dioxide were used as a refrigerants in VCR systems. Refrigerants like $\mathrm{CH} 4, \mathrm{C} 2 \mathrm{H} 4, \mathrm{C} 2 \mathrm{H} 6$, etc., were tested as working fluids in refrigeration system and exercised in medium and low temperature applications during the period of two decades from 1910. New refrigerant group namely Chlorofluorocarbons (CFCs) were introduced in 1930s as working fluid in VCR system by E.I. du Pont de Nemours and significant developments were reached in refrigeration field. Thermo-physical properties of CFCs fulfill the various requirements of VCR system at different operating conditions. Even though the refrigeration system performs better with CFCs, they are vulnerable to the ozone depletion due to their chlorine compounds. Ferdinand Carre has developed Vapour Absorption Refrigeration (VAR) system in 1858 with the working fluid of water and sulphuric acid. Platen and Munters developed a three fluids absorption refrigeration system without the use of power absorbing element (pump) in 1922. The low grade energy like heat sources from geothermal energy, waste heat from furnace, IC engine and generator is sufficient to run the VAR system. During the initial stages of VAR system, Ammonia-water $\left(\mathrm{NH}_{3}-\mathrm{H}_{2} \mathrm{O}\right)$ was used as working fluid in which $\mathrm{NH}_{3}$ and $\mathrm{H}_{2} \mathrm{O}$ act as a refrigerant and absorbent respectively. So far, previous researches indicated that among these four sub-coolers, CAS yielded the highest improvement in COP of about $28.9 \%$, followed by DMS (27\%), LSHX (18\%) and IMS (7.5\%). ${ }^{11}$

\subsection{Energy requirements for refrigeration system:}

Effective utilization of supplied (input) energy will be the key parameter towards maximizing the performance of any system. The day by day energy requirement is of the swelling trend in the global scenario due to the improved living standards and human comfort with the usage of sophisticated devices like heaters, chillers, refrigerators and air-conditioning systems. Energy requirement for refrigeration systems is escalating very rapidly in domestic and industrial applications like domestic refrigerators, beverage and food processing industries, cold storages, frozen meat storages, milk chilling plants, ripening chambers and medical storage applications. Energy efficiency is the important tool which measures the performance of the refrigeration system. Energy requirement of major house hold appliances are shown in Figure 1.1. Among the various appliances, refrigerators are placed in second position in terms of annual power consumption. Throughout one year period, the utilization time is also more in case of refrigerators. This shows that refrigerators are more energy consuming appliance in domestic applications.

Cooling effect for food preservation and low temperature applications makes more usage of refrigerators in industrial applications. The energy spent for refrigeration systems in domestic and industrial applications is elevated due to more usage in the respective fields. Hence energy efficient techniques are the most required one in the refrigeration systems in favor of environment and international protocols. 


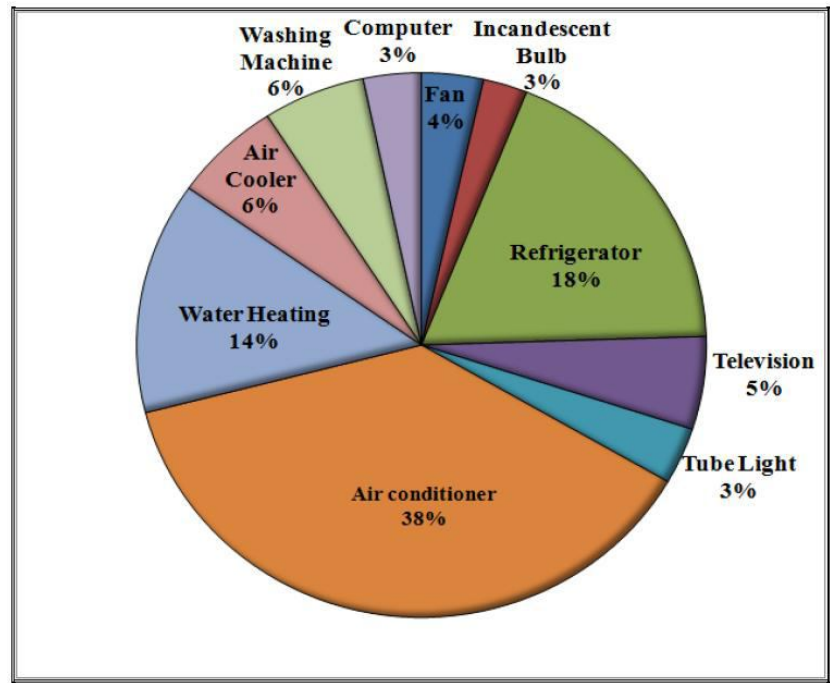

Figure 1.1 Energy consumption pattern of major household appliance

\subsection{Types of refrigeration system:}

Generally refrigeration systems are classified as

- Vapour Compression Refrigeration system (High grade energy)

- Vapour Absorption Refrigeration system (Low grade energy)

- Thermoelectric refrigeration system

- Steam-jet refrigeration system

\subsection{Vapour Compression Refrigeration System :}

Vapour compression refrigeration cycle is used in most of the refrigeration systems due to its advantageous features like better thermodynamic properties of refrigerant, higher refrigerating effect, higher Coefficient of Performance (COP) etc., The vast applications of this refrigeration cycle includes domestic and commercial refrigerators, food preservation plants, refrigerated vehicles,

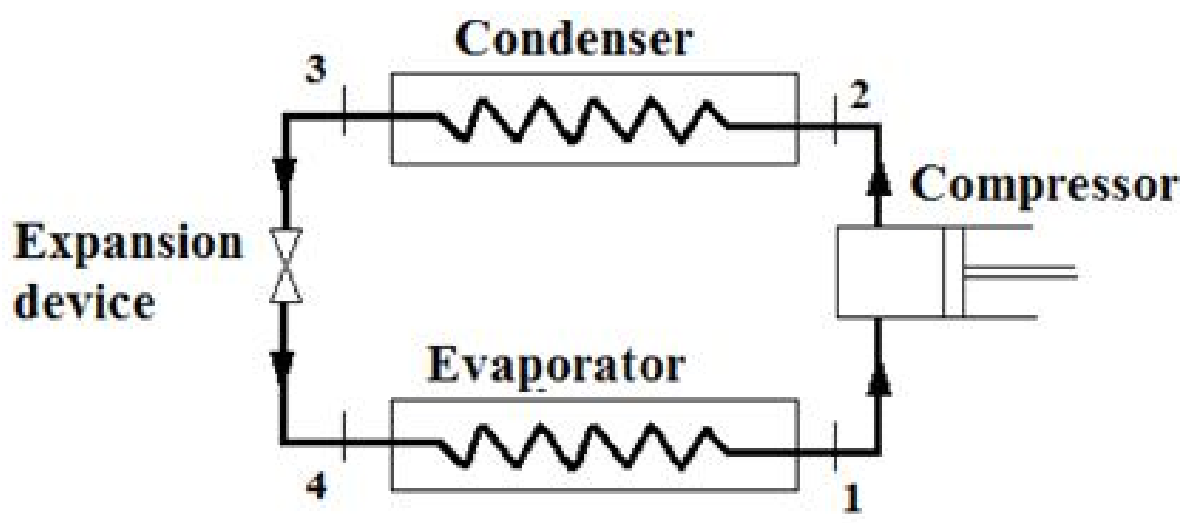

Figure 1.2 Schematic arrangement of vapour compression refrigeration system 


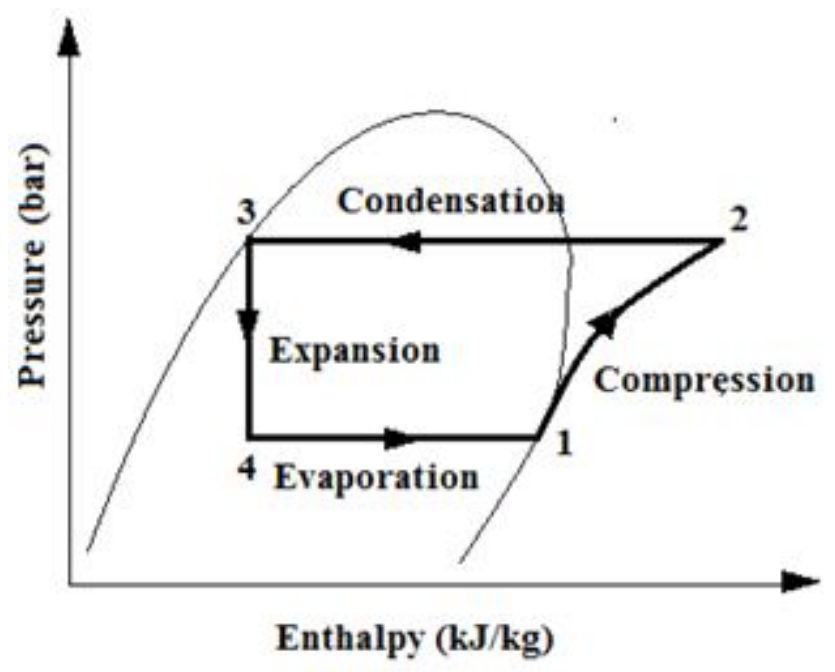

Figure $1.3 \mathrm{p}$-h diagram of vapour compression refrigeration cycle

\subsection{Vapour Absorption Refrigeration System :}

Environment friendly cooling methods are mandatory to reduce the usage of high grade energy in refrigeration systems. Thermal energy (low grade energy) can be applied to produce the cooling effect instead of mechanical energy (high grade energy) in refrigeration system. VAR system is chosen among the various refrigeration systems due to the usage of low grade energy sources like geothermal energy, exhaust gases from automobiles and industries, Solar energy etc., VAR system uses the most famous working pairs of $\left(\mathrm{NH}_{3}-\mathrm{H}_{2} \mathrm{O}\right)$ and $\left(\mathrm{LiBr}-\mathrm{H}_{2} \mathrm{O}\right)$.

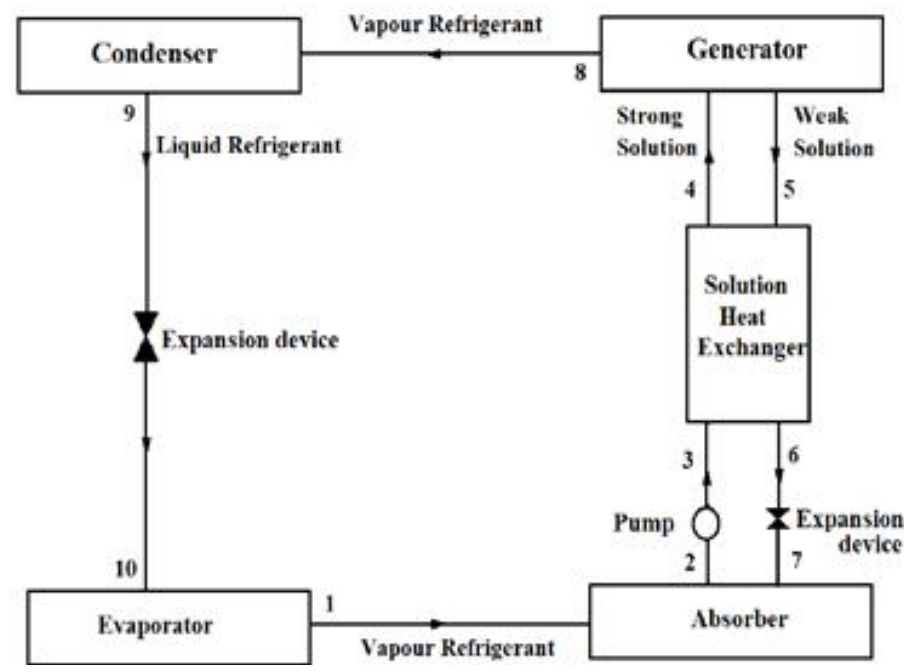

Figure 1.5 Schematic arrangement of single effect vapour absorption Refrigeration system

During evaporation of refrigerant in the generator, the weak refrigerant solution (5) returns into the 
absorber where the vapour refrigerant from evaporator (1) is reabsorbed and completes the cycle. Heat content of weak refrigerant solution can be effectively used to heat the strong refrigerant solution coming from the pump (3) through a solution heat exchanger. Effective heat transfer between these solutions enhances the performance of VAR system. In order to get an equilibrium pressure in the absorber, an expansion device is used after the solution heat exchanger (7) in the weak refrigerant solution flow line. Thermoelectric refrigeration system is broadly discussed in the chapter 5 . Steam-jet refrigeration system is not focused in this research work.

1.6 Experimental setup and methodology

There is two methods which I have done this experiments.

[1] Performance analysis of vapour compression refrigeration system under various evaporator loads

[2] Performance analysis of vapour compression refrigeration system with thermoelectric sub cooling

1.6.1 Performance analysis of vapour compression refrigeration system under various evaporator loads :

Based on the ecological condition and environmental robustness, identification of alternate refrigerants and economical mode of operation are the essentials for current refrigeration systems. The optimum quantities of materials to be cooled by the refrigerators are not considered so far for liquid materials cooling applications. Normally the considerations are overloading or under loading of the refrigeration systems. Condition of over loading involves large amount of heat to be removed from the evaporator chamber and the condition of under loading involves comparatively less amount of heat to be removed from the evaporator chamber. The huge amount of energy in terms of work input to compressor is used to produce low temperature applications. The quantity of work input supplied to the compressor will significantly influence the performance of the refrigeration system. Energy requirement to run the refrigeration system mainly depends upon the quantity of the materials to be loaded in the evaporator. Energy efficient refrigeration system can be achieved by proper loading of evaporator. Identification of optimum/economic loading of evaporator is an important criterion for energy efficient refrigeration systems.

\subsubsection{Performance analysis of vapour compression refrigeration system with thermoelectric sub cooling:}

The objective of this chapter is to improve the performance of simple VCR system using thermoelectric sub cooling under different loading conditions in the evaporator. Most of the refrigeration systems are equipped with air cooled condenser due to their quick condensation effect on the refrigerant with natural or forced convection. Air cooled condensers are employed in small capacity machines like domestic refrigerators, water coolers etc., Since the effect of air cooled condensation is not sufficient in the refrigeration systems, reduction in refrigerating effect and COP will occur.

Sub cooling is the technique which can enhance the refrigerating effect and COP through efficient atomization of subcooled refrigerant in the expansion device, this indirectly reduces the compressor work input and increases the refrigerating effect causing the performance enhancement of the refrigeration system. HCM has the potential to be used as an alternate refrigerant to HFC and CFC compounds due to their lower GWP and zero ODP. Chapter 3 recommends the HCM as an alternative and eco friendly refrigerant for any refrigeration system. This chapter discusses the performance of simple VCR system with thermoelectric subcooling using $\mathrm{HCM}$ as a working fluid. The part load performance analysis has been executed to identify the economical mode of operation among various loading conditions namely 25, 50,75 and 100\%. Various performance indexes like work input to the compressor, condenser heat rejection rate, refrigerating effect and $\mathrm{COP}$ are investigated under these loading conditions with thermoelectric subcooling. 
1.7 experimental arrangement of vapour compression refrigeration system :

The main components of simple VCR system are compressor, condenser, expansion device and evaporator. Thermodynamic analysis of any refrigeration system has been represented by energy flow in and out of the system as per the statement of first law of thermodynamics. Heat and energy balance of each component will make the perfect assessment of any thermal system. Hermetically sealed compressor (Single phase, $220-240 \mathrm{~V}, 50 \mathrm{~Hz}$ ) is used to compress the vapour refrigerant from the evaporator to condenser pressure. Air cooled condenser condenses the high pressure and high temperature vapour refrigerant into liquid through constant pressure heat rejection process. High pressure liquid refrigerant gets expanded through the expansion device. Stirring action is produced by stirrer which is attached with the system to attain the uniform cooling effect. Experimental arrangement of simple VCR system is shown in Figure 4.1. Figure 4.2 represents the photographic view of experimental arrangement of simple VCR system. The measuring instruments like pressure gauges, temperature sensors are also indicated in the diagram. Temperature at various state points are measured using the Resistance Temperature Detector K-type thermocouples with accuracy of $+0.1{ }^{0} \mathrm{C}$. Bourdon tube pressure gauges with the working range of 0-300 psi and 0-150 psi having the accuracy of +1 psi are used to measure the pressure at various state points. Energy meter is also prearranged with the experimental arrangement. Removal of moisture from the experimental arrangement and leak test has been carried out before charging of the refrigerant in the refrigeration system. As per the recommendation from Chapter 3, the mixture of R290 and R600a with mass fraction of 0.5:0.5 is charged as refrigerant in this experimental analysis. In order to identify the various loading conditions in the evaporator, the following preliminary work has been carried out. Various loading conditions are considered for analyzing the performance of the VCR system with water as a substance in the evaporator. Initially the evaporator is loaded with $10 \%$ of its total volume for the investigation, further the load is increased by $10 \%$ for each iterations and totally 10 iterations are performed to attain $100 \%$ of loading. The results obtained for these loading conditions are analyzed and found that, from $10 \%$ of loading to around $80 \%$ of loading the performance of the VCR system is in improving order in terms of refrigerating effect and COP. When the load is further increased it starts to decrease in the refrigerating effect and COP due to more heat absorption in the evaporator and more work input requirement in the compressor. Hence to reduce the complexity of the analysis only four different loading conditions specifically 25, 50, 75 and 100\% of loading are considered in this research work for further analysis. Part load performance analysis is to be carried out under different loading conditions, therefore the no load condition in the evaporator is not accounted in this investigation.

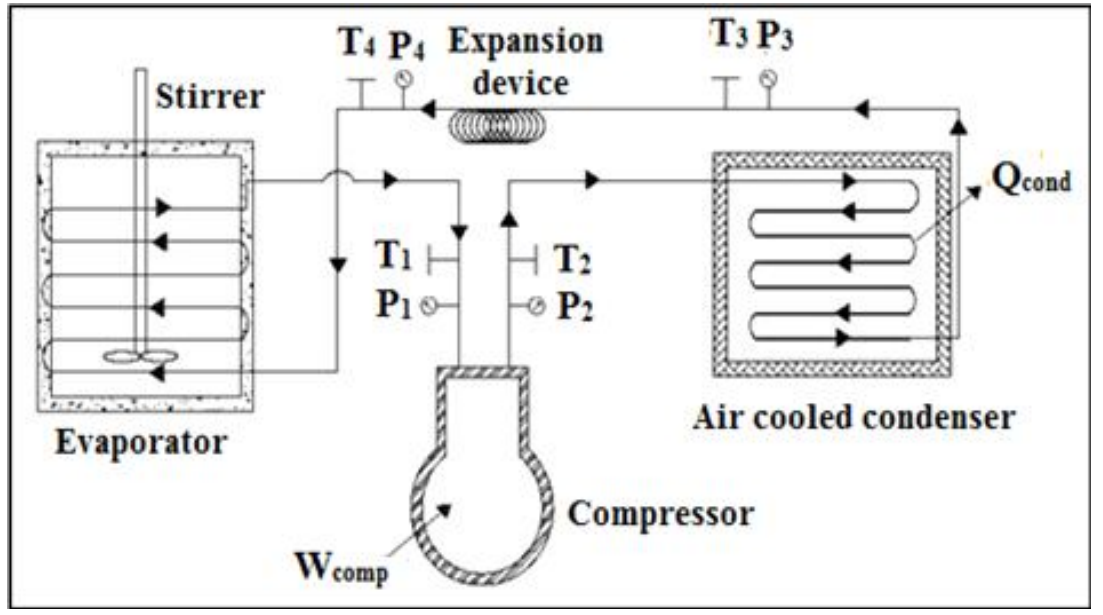

Figure 3.1 Experimental arrangement of simple VCR system 


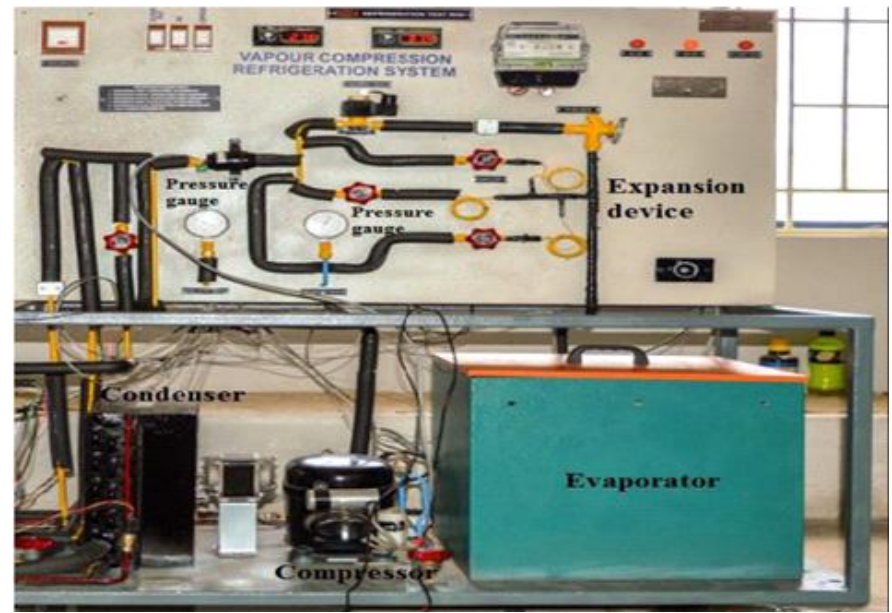

Figure 3.2 Photographic view of experimental arrangement of simple VCR system

\subsection{Methodology :}

The part load performance analysis is carried out to identify the economic loading of refrigeration system under various loading conditions namely $25,50,75$ and $100 \%$ in the evaporator by filling the water in terms of its entire volume. Initially the evaporator is filled with $25 \%$ of volume by water. Cycling test (on/off) is performed for all loading conditions in the Evaporator. Experimental observations are noted down for the water temperature in the evaporator from 26 to $2^{\circ} \mathrm{C}$. The observations are recorded for every $2^{\circ} \mathrm{C}$ drop in water temperature in the evaporator. During the experimentation the measurements like pressure and temperature at various state points $(1,2,3$ and 4$)$ are recorded.

Based on the measured pressure and temperature, the enthalpy value of each state points of the refrigeration system is calculated using the thermodynamic properties of HCM1. Various thermodynamic properties of HCM1 are obtained from the REFPROP software. Enthalpy values at different state points of the VCR system namely h1, h2, h3 and h4 are estimated using the following equations.

$$
\begin{aligned}
& \mathrm{h}_{1}=\mathrm{h}_{\mathrm{g} 1}+\mathrm{c}_{\text {pvap } 1}\left(\mathrm{~T}_{\text {sup } 1}-\mathrm{T}_{\text {sat1 }}\right) \\
& \mathrm{h}_{2}=\mathrm{h}_{\mathrm{g} 2}+\mathrm{c}_{\text {pvap } 2}\left(\mathrm{~T}_{\text {sup } 2}-\mathrm{T}_{\text {sat2 } 2}\right) \\
& \mathrm{h}_{3}=\mathrm{h}_{\text {liq } 3}-\mathrm{c}_{\mathrm{pliq} 3}\left(\mathrm{~T}_{\text {sat3 }}-\mathrm{T}_{\text {sub3 }}\right) \\
& \mathrm{h}_{3}=\mathrm{h}_{4}
\end{aligned}
$$

The performance indexes like work input to compressor $\left(\mathrm{W}_{\text {comp }}\right)$, condenser heat rejection rate $\left(\mathrm{Q}_{\text {cond }}\right)$, refrigerating effect $\left(\mathrm{Q}_{\mathrm{evp}}\right)$ and $\mathrm{COP}$ are evaluated based on the unit mass flow rate of refrigerant in the refrigeration system and is given in equations (3.3, 3.6, 3.9 and 3.10 respectively) in chapter 3 . The same procedure is repeated for 50,75 and $100 \%$ loading conditions respectively. 


\section{Result:}

1.9 Effect of Water Temperature in the Evaporator on Work input to the Compressor at Various Loading Conditions :

The work input to the compressor should be as low as possible in the case of an efficient refrigeration system, being the requirement; the recommendations can be towards the lowest value. Since the $75 \%$ loading condition consumed lowest work input to the compressor compared to that of all other loading conditions, the interpretation from Figure 5.9 concludes that it could be considered as the economic mode of operation for the refrigeration system in terms of work input to the compressor.

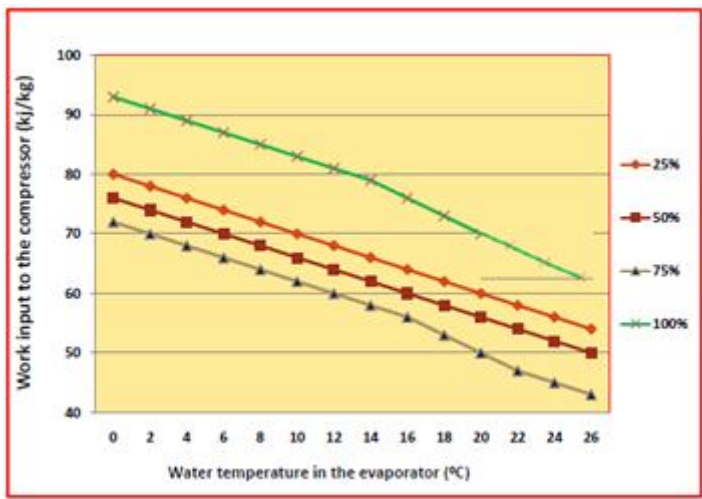

Figure 4.1 Effect of water temperature in the evaporator on work input to the compressor at various loading conditions with TEC

\subsection{Effect of Water Temperature in the Evaporator on Condenser Heat Rejection Rate at Various Loading} Conditions :

The variation in condenser heat rejection rate is represented in Figure 4.3 for different loading conditions. The maximum heat rejection rate is achieved during the $100 \%$ loading condition compared to all other mode of operations. During 25\% loading condition, the heat rejection rate at air cooled condenser with TEC is comparatively less than that of other loading conditions. Even though 100\% loading has higher heat rejection rate it lacks with other indexes namely work input to the compressor, refrigerating effect and COP. Thus $75 \%$ loading condition will be the optimum selection "for better performance of the refrigeration system with TEC".

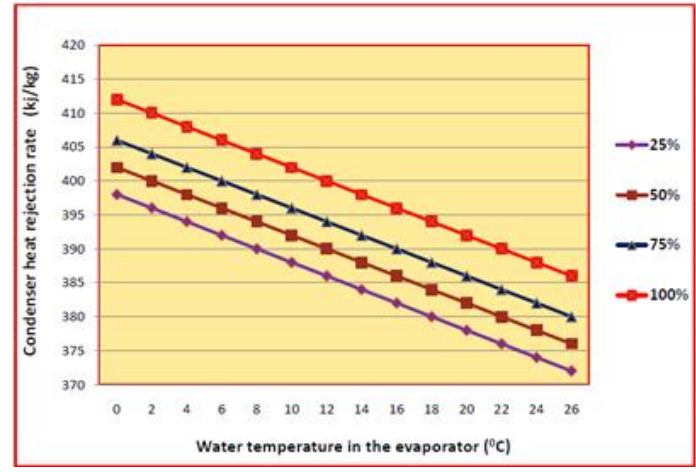

Figure 4.3 Effect of water temperature in the evaporator on condenser heat rejection rate at various loading conditions with TEC 
1.11 Effect of Water Temperature in the Evaporator on Refrigerating Effect at Various Loading Conditions :

Refrigerating effect has been evaluated with respect to water temperature in the evaporator at different loading conditions and is shown in Figure 4.4. The maximum refrigerating effect is found for $75 \%$ loading condition which is higher than that of 25,50 and $100 \%$ loading conditions. The minimum refrigerating effect is found at $100 \%$ loading condition due to the requirement of more cooling effect of the water from $26^{\circ} \mathrm{C}$ to $2{ }^{\circ} \mathrm{C}$. Higher refrigerating effect is the favorable requirement of any refrigeration system. Hence the conclusion will be "for better performance of the refrigeration system, the evaporator can be loaded at $75 \%$ loading condition for liquid material cooling applications by VCR system with TEC".

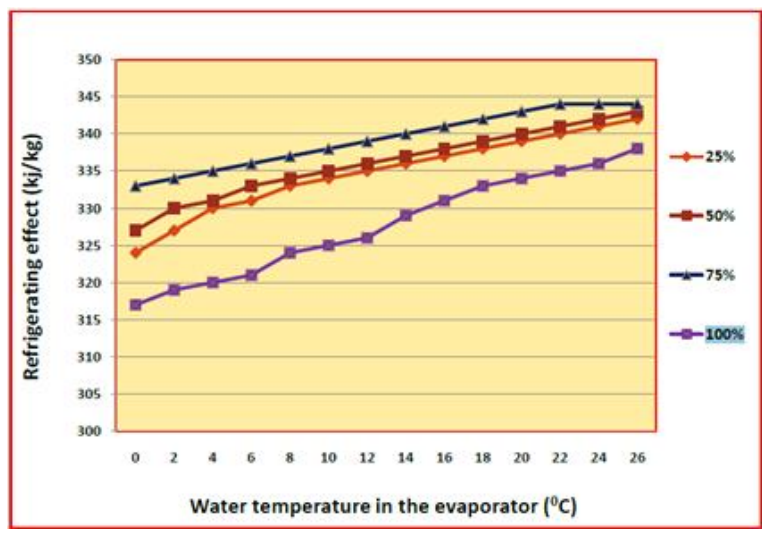

Figure 4.4 Effect of water temperature in the evaporator on refrigerating effect at various loading conditions

\subsection{Percentage change in actual COP:} with TEC

In following section actual COP is calculated and compared for both cases and graph is plotted between Load Vs Actual COP. The heat loss by conduction is added to the refrigerating load on the evaporator for ambient temperature along with load of stirrer motor 40 watts for uniform distribution of the temperature. From the graph it is observed that when load on the evaporator is varied there is increase in actual COP when TEC is integrated with VCR system for subcooling of refrigerant. For $18 \mathrm{Kg}$ load on evaporator there is maximum increase in actual COP is $17.21854 \%$.

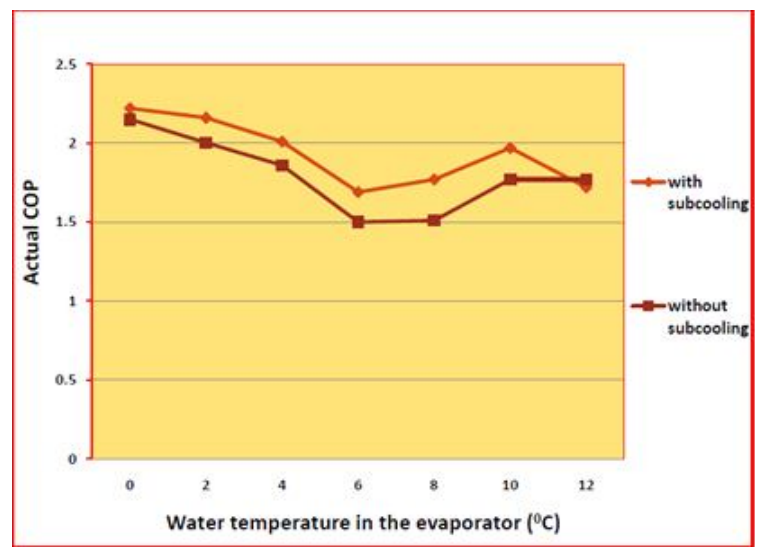

Figure 4.7 Effect of water temperature in the evaporator on actual COP at various loading conditions with TEC 


\subsection{Conclusion}

- HCM1 has satisfied the primary need of eco friendly refrigerant and has the COP enhancement of $5.9-10 \%$ in the simulation analysis.

- Work input to the compressor gets reduced by 4.49,2.59 and 27.49\% compared to the operation of 25, 50 and $100 \%$ loadings respectively.

- Comparatively increased refrigerating effect ensures the orientation of $75 \%$ loading condition.

\section{References}

1. Adeyanju, AA \& Compton, W., "Theoretical determination of a thermoelectric module and heat sinks sizing", International Journal of Electrical and Power Engineering, vol. 4, no. 2, pp.66-72 (2010).

2. Akash, BA \& Said, SA., "Assessment of LPG as a possible alternative to R-12 in domestic refrigerators, Energy Conversion and Management, vol. 44, no. 3, pp. 381-388 (2003).

3. Arora, CP, Refrigeration and Air Conditioning, Tata McGrew- Hill Publishing Company Ltd., New Delhi (2004).

4. Ashrae Handbook, Refrigeration, SI edition, American Society of Heating, Refrigerating and AirConditioning Engineers, Inc., Atlanta (2010).

5. Astrain, D, Martinez, A \& Rodriguez, A., "Improvement of a thermoelectric and vapour compression hybrid refrigerator", Applied Thermal Engineering, vol. 39, pp. 140- 150 (2012).

6 Baskaran, A \& Koshy Mathews, P., "A Performance comparison of vapour compression refrigeration system using various alternative refrigerants", International Journal of Scientific and Engineering Research, vol. 3, no.10, pp.1-7 (2012).

7. Bernard Thonon, "A review of hydrocarbon two-phase heat transfer in compact heat exchangers and enhanced geometries", International Journal of Refrigeration, vol. 31, no.4, pp. 633-642 (2008).

8. Bilal Ahmed Qureshi \& Syed M Zubair, "The effect of refrigerant combinations on performance of a vapor compression refrigeration system with dedicated mechanical sub-cooling ", International Journal of Refrigeration, vol. 35, no. 1, pp. 47-57 (2012).

9. Bolaji, BO, "Effects of Sub-Cooling on the performance of R12 alternatives in a domestic refrigeration system", Thammasat International Journal of Science and Technology, vol. 15, no.1, pp. 12- Bolaji, BO 2010 (2010),

10. "Experimental study of R152a and R32 to replace R134a in a domestic refrigerator", International Journal of Energy, vol.35, no. 9, pp. 3793-3798.

11. Sumerua, K.* , Sukrib,c,M.F., Falahuddina, M.,A., Setyawana A., 'A REVIEW ON SUB-COOLING IN VAPOR COMPRESSION REFRIGERATION CYCLE FOR ENERGY SAVING', Jurnal Teknologi, 81(5), pp. 155-170 (2019). 